\title{
Enhancing the understanding of the glycerol to lactic acid reaction mechanism over AuPt/TiO 2 under alkaline conditions
}

\author{
Christopher Evans ${ }^{a}$, Mark Douthwaitea, James H. Cartera, Samuel Pattisson ${ }^{a}$, Simon \\ Kondrat $^{\mathrm{a}, \mathrm{b} *}$, Donald Bethell ${ }^{\mathrm{a}}$, David J. Knight ${ }^{\mathrm{a}}$, Stuart H. Taylor ${ }^{\mathrm{a}}$, Graham J. Hutchings ${ }^{\mathrm{a} *}$
}

${ }^{a}$ Cardiff Catalysis Institute, School of Chemistry, Cardiff University, Main Building, Park Place, Cardiff, CF10 3AT, UK

${ }^{b}$ Department of Chemistry, Loughborough University, Loughborough, Leicestershire, LE113TU, U.K

* Correspondence to Simon Kondrat (E-mail: s.kondrat@lboro.ac.uk) and Graham J. Hutchings (Email: hutch@cardiff.ac.uk)

\begin{abstract}
The oxidation of glycerol under alkaline conditions in the presence of a heterogeneous catalyst can be tailored to the formation of lactic acid; an important commodity chemical. Despite recent advances in this area, the mechanism for its formation is still a subject of contention. In this study, we use a model $1 \mathrm{wt} . \% \mathrm{AuPt} / \mathrm{TiO}_{2}$ catalyst to probe this mechanism through conducting a series of isotopic labelling experiments with $1,3-{ }^{13} \mathrm{C}$ glycerol. Optimisation of the reaction conditions was first conducted to ensure high selectivity to lactic acid in the isotopic labelling experiments. Selectivity to lactic acid increased with temperature and concentration of $\mathrm{NaOH}$, but increasing the $\mathrm{O}_{2}$ pressure appeared to only influence rate of reaction. Using $1,3-{ }^{13} \mathrm{C}$ glycerol we demonstrate that conversion of pyruvaldehyde to lactic acid proceeds via a base-promoted 1,2-hydride shift, to produce lactic acid. There was no evidence to suggest that this occurs via a 2,1-methide shift under the conditions used in this study.
\end{abstract}

TAGS: Glycerol Oxidation, Lactic Acid, Mechanism, Isotopic Labelling 


\section{Introduction}

Glycerol is a major by-product formed from the synthesis of first generation bio-fuels. Recent advances in this area, supported by substantial investment, has resulted in a significant increase in the quantity of glycerol produced per annum and this is projected to further increase over the coming years. As such, the market value of glycerol has decreased markedly and an abundance of glycerol is available. ${ }^{1}$

The highly functionalised nature of glycerol allows for many different valorisation strategies. One such strategy involves the aerobic oxidation of glycerol over noble metal supported catalysts, which can result in the formation of many different value-added products. (Scheme 1). Since Rossi and Prati $^{2}$ first established that supported Au catalysts were highly active for the aerobic oxidation of alcohols, much research has been published on the oxidation of glycerol., ${ }^{3,4}$ The complexity of the product distribution, formed from various parallel and sequential processes, makes this reaction an interesting model system for the study of heterogeneous catalysis; a deeper understanding of the influence of different metals, support properties and particle size effects has been established. ${ }^{3,5-7}$

The current understanding is that the reaction, as shown in Scheme 1, involves an initial oxidation of an alcohol function to carbonyl producing a mixture of reaction intermediates dihydroxyacetone (DHA) or glyceraldehyde (GLD). This mixture reacts further via two competing pathways, further oxidation or dehydration. Unravelling the factors which promote each of the pathways is difficult, since the initial alcohol oxidation is considered to be the rate determining step (RDS). ${ }^{8}$ The further oxidation pathway converts the GLD or DHA sequentially into glyceric acid (GA) and tartronic acid (TA). However an additional competitive pathway arises from GA, which involves the scission of $\mathrm{C}-\mathrm{C}$ bonds which many attribute to the in-situ formation of $\mathrm{H}_{2} \mathrm{O}_{2} .{ }^{9}$ This can allow for the formation of $C_{2}$ and $C_{1}$ oxidation products such as glycolic acid (GLO), oxalic acid (OA) and formic acid (FA). By contrast, if dehydration is favoured, pyruvaldehyde (PALD) or its corresponding enol is formed. PALD can then undergo a rearrangement to produce lactic acid (LA). The nature of this rearrangement reaction remains a subject of much debate; various publications have suggested that this proceeds via a 1,2-hydride shift, commonly referred to as an intramolecular Cannizzaro reaction, ${ }^{10,11}$ whilst others propose a 2,1-methide shift, analogous to a benzilic acid rearrangement. ${ }^{12}$

Of the reaction products described, the conversion of glycerol into LA has perhaps generated the most interest in recent years. LA can be used as a reagent to produce ethyl lactate, a common biodegradable solvent, and as a monomer used to produce the bioplastic polylactic acid. ${ }^{13}$ The development of such polymers has perhaps become even more pressing in recent years due to plastic wastes infiltrating ecosystems all over the world. This has rightly led to very public concerns and 
mounted pressure on the plastics industry to develop greener and more sustainable products. Many studies have uncovered catalysts which can provide high selectivity to LA from glycerol conditions and developments made in this area were recently documented in an in-depth review. ${ }^{14}$

Under base-free conditions, the initial alcohol oxidation is followed by Brønsted acid catalysed dehydration of a primary alcohol; many reports have aligned reaction selectivity to LA with this catalytic property. ${ }^{6}$ However, there is much evidence to suggest that Lewis acid sites are responsible for the rearrangement from PALD to LA. ${ }^{15,16}$ Interestingly reaction selectivity to LA also improves as the quantity of base in the system increases, ${ }^{17}$ suggesting that the dehydration of the GLD is favoured over its direct oxidation to GA. The influence of the catalyst on this dehydration reaction under these conditions remains elusive. DHA and GLD, although never observed under alkaline conditions, are considered to exist in equilibrium; ${ }^{18}$ the rate of isomerisation between these two compounds is influenced by $\mathrm{pH}^{19}$ As such, it is likely that the proportion of these two compounds in solution and how they interact with the catalyst, is ultimately what dictates reaction selectivity.

In this study, we use isotopic labelling experiments to confirm the reaction mechanism for the formation of LA from PALD using $1,3-{ }^{13} \mathrm{C}$ glycerol. High LA selectivity during this study is ensured by a thorough optimisation of reaction conditions in the presence of a model $1 \mathrm{wt} . \% \mathrm{AuPt} / \mathrm{TiO}_{2}$ catalyst. These optimisation reactions also led to important conclusions regarding the competitive mechanisms which take place on the catalyst surface; GLD and DHA can either undergo catalytic oxidation to GA and TA or dehydration to PALD.

\section{Experimental}

\section{Materials (source, purity)}

Acetic acid (Sigma-Aldrich, $\geq 99.7 \%$ ); Chloroauric acid (Strem, $99.8 \%$ ); Chloroplatinic acid hexahydrate (Sigma Aldrich, ACS reagent, 37.5 \% Pt basis); Formic acid (Sigma Aldrich, $\geq 98 \%$ ); Glyceric acid (TCl, 40 wt.\% in water); Glycerol (Sigma-Aldrich, $\geq 99.5 \%$ ); Glycolic acid (Sigma-Aldrich, 99\%); Concentrated Hydrochloric Acid (Fisher Scientific, ca 37 \%) Lactic Acid (Sigma-Aldrich, 85 wt.\% in $\mathrm{H}_{2} \mathrm{O}$ ); Concentrated Nitric Acid (Fisher Scientific, 70 \%); Oxalic acid (Sigma-Aldrich, $\geq 99.99 \%$ ); Phosphoric Acid (SigmaAldrich, (85 wt. \% in $\mathrm{H}_{2} \mathrm{O}$ ); Polyvinylalcohol (Sigma-Aldrich, 80 \% Hydrolysed); Pyruvic Acid (SigmaAldrich, 98 \%) Sodium Borohydride (Sigma-Aldrich, 99.99 \%); Sodium Hydroxide (Fischer Scientific, $99.3 \%$ ); Concentrated Sulfuric Acid (Fisher Scientific, >95 \%); Tartronic acid (Sigma-Aldrich, $\geq 97 \%$ ); Titania P25 (Degussa, $\geq 99.5 \%$,); Water, (Fisher Scientific, HPLC grade). 


\section{Definitions}

$$
\text { Conversion }(\%)=\frac{\text { Mol of glycerol converted }}{\text { Initial mol of glycerol }} \times 100
$$

Equation 1: Expression to calculate the conversion of glycerol in a typical glycerol oxidation experiment. Conversion is expressed as a percentage.

$$
\text { Selectivity of product } A(\%)=\frac{\text { Mol of product } A}{\text { Mol of reactant converted }} \times 100
$$

Equation 2: Expression to calculate the reaction selectivity to a given product, in this case Product $A$, in a typical glycerol oxidation experiment. Selectivity is expressed as a percentage.

$$
\text { Carbon Mass Balance }(\%)=\frac{\text { Mol of Carbon from Glycerol }}{\text { START }} \times 100
$$

Equation 3: Expression to calculate the carbon mass balance $(C M B)$ in a given glycerol oxidation

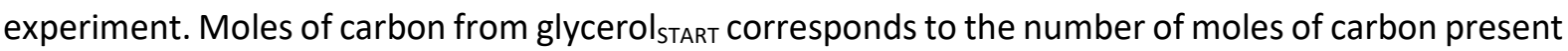
at the start of the reaction. Total moles of carbon corresponds to the sum of the carbon moles in reaction products and residual glycerol, in a given sample.

\section{Catalyst preparation}

The model 1 wt.\% Au-Pt/TiO 2 catalyst was prepared by the sol-immobilisation methodology, using polyvinyl alcohol (PVA) as the stabilising agent. The experimental procedure used for the synthesis of catalyst (2 g) is as follows: , $\mathrm{HAuCl}_{4}(0.82 \mathrm{~mL}, 12.25 \mathrm{~g} / \mathrm{L})$ and $\mathrm{H}_{2} \mathrm{PtCl}_{6}(2.052 \mathrm{~mL}, 4.85 \mathrm{~g} / \mathrm{L})$ were added to a beaker $(1 \mathrm{~L})$ containing $\mathrm{H}_{2} \mathrm{O}(800 \mathrm{~mL}$ ) and a magnetic stirrer. Aqueous PVA ( $1.3 \mathrm{~mL}$, from $0.1 \mathrm{~g}$ PVA in $10 \mathrm{~mL} \mathrm{H}$ O) was subsequently added and left to stir for $15 \mathrm{~min}$. Freshly prepared aqueous $\mathrm{NaBH}_{4}$ (3.928 mL, $0.2 \mathrm{M}$ ) was then added instantaneously to the solution, forming a yellow/grey sol. The mixture was then stirred for $30 \mathrm{~min}$ before acidification to $\mathrm{pH} 2$, through the dropwise addition of concentrated $\mathrm{H}_{2} \mathrm{SO}_{4}$. Powdered $\mathrm{TiO}_{2}(1.98 \mathrm{~g})$ was added and the solution was stirred for an additional $1 \mathrm{~h}$. The resulting mixture was then filtered under vacuum, washed with deionised water $(2 \mathrm{~L})$ and dried in a conventional fan oven $\left(16 \mathrm{~h}, 110^{\circ} \mathrm{C}\right)$. The recovered solid was ground into a powder using an agate pestle and mortar.

\section{Glycerol oxidation}


All catalyst testing was conducted using a Radley's starfish reactor, using the following experimental procedure: To a round bottom flask $(50 \mathrm{~mL})$, aqueous glycerol solution $(10 \mathrm{~mL}, 0.6 \mathrm{M})$, aqueous $\mathrm{NaOH}$ $(10 \mathrm{~mL}, 0.6-2.4 \mathrm{M}), \mathrm{AuPt} / \mathrm{TiO}_{2}(58.2 \mathrm{mg})$ and a magnetic stirrer were added. The flask was subsequently sealed, purged three times with the reactant gas and charged with the desired pressure of $\mathrm{O}_{2}$ or $\mathrm{He}(0.5-4 \mathrm{barG})$. The gas inlet remained open over the duration of the experiments to ensure that the system was maintained at the desired pressure. The flask was then secured to the reactor, which had been preheated to the desired reaction temperature $\left(40-120^{\circ} \mathrm{C}\right)$. Once secured, the magnetic stirring (1000 RPM) and reaction timer were initiated. In some reactions, $0.5 \mathrm{~mL}$ samples were taken at specific intervals (typically 30, 60, 120 and $240 \mathrm{~min}$ ). For this process, the flask was removed and cooled with an ice bath, prior to de-pressurisation. Once the sample was taken, the same purging and charging procedure was repeated and the flask was re-secured to the reactor. The samples taken from the reactions were immediately diluted 10 fold in deionised water, to quench the reaction, and subsequently filtered. Quantification of the samples was conducted using an Agilent 1260 Infinity HPLC equipped with ultraviolet and refractive index detectors, using an external calibration method. The products were separated at $50{ }^{\circ} \mathrm{C}$, over a Metacarb $67 \mathrm{H}$ column using an isocratic mobile phase of aqueous $\mathrm{H}_{3} \mathrm{PO}_{4}\left(0.1 \mathrm{wt} . \%\right.$, flow rate $\left.=0.6 \mathrm{~mL} \mathrm{~min}{ }^{-1}\right)$.

\section{Catalyst Characterisation}

Brunauer Emmett Teller (BET) surface area measurements were conducted using a Quadrasorb surface area analyser. A 5-point isotherm of each material was measured, using $\mathrm{N}_{2}$ as the adsorbate gas. Samples were degassed at $250^{\circ} \mathrm{C}$ for $2 \mathrm{~h}$ prior to analysis.

Transmission electron microscopy (TEM) was carried out with a Jeol 2100 with a LAB6 filament operating at $200 \mathrm{kV}$. Each sample was prepared by dispersing the powdered catalyst in ethanol and dropping the suspension onto a lacey carbon film over a 300 mesh copper grid.

The metal loading of the catalyst was determined by Microwave Plasma - Atomic Emission Spectrometry (MP-AES). For this, catalyst $(50 \mathrm{mg}$ ) was added to a volumetric flask (50 mL) containing freshly prepared aqua regia $(5 \mathrm{~mL})$, ensuring the sample was fully submerged in the liquid. The catalyst was then left for $24 \mathrm{~h}$ to ensure full dissolution of metal after which the flask was filled to $50 \mathrm{~mL}$ with deionised water. The solution was subsequently filtered using a PTFE syringe filter (0.45 $\mu \mathrm{m})$, to remove any residual particulates. The liquid effluent was then analysed using an Agilent 4100 MP-AES. A series of solutions were made using Au (Agilent, 1000 ppm) and Pt (Agilent, 1000 ppm) standards. The calibrations and reaction effluent was subsequently analysed at multiple wavelengths for each element, to ensure accuracy. 
The ${ }^{13} \mathrm{C}$ and ${ }^{1} \mathrm{H}$ NMR spectra were obtained using a Bruker Avance $400 \mathrm{MHz}$ DPX spectrometer. The chemical shifts for ${ }^{1} \mathrm{H}$ NMR were run in deuterated chloroform $\left(\mathrm{d}-\mathrm{CDCl}_{3}\right)$ or deuterated dimethylsulfoxide ( $\mathrm{d}_{6}$-DMSO).

\section{Results and Discussion}

\section{Synthesis and characterisation of the model AuPt/TiO 2 catalyst}

Previous publications have reported that supported AuPt catalysts are effective for the aerobic oxidation of glycerol to LA, under alkaline conditions. ${ }^{17}$ Despite this, the mechanism for the formation of LA remains elusive. Derivation of the mechanism for this transformation is crucially important, as such detail can be fed back into catalyst design. For this reason, we synthesised a $1 \mathrm{wt} . \% \mathrm{AuPt} / \mathrm{TiO}{ }_{2}$ catalyst by the sol-immobilisation method, to use as a model to study the mechanism in this reaction. This technique was used as it highly reproducible and typically produces supported metal catalysts with narrow particle size distributions (PSDs). ${ }^{20}$

TEM was performed on the synthesised catalyst, to confirm that it possessed the desired dispersion of AuPt. Images from this characterisation and the corresponding PSDs are displayed in Figure 1. The data demonstrates that the $\mathrm{Au}$ and Pt are indeed well dispersed in this catalyst. Here, a mean particle size of $1.68 \mathrm{~nm}$ was calculated with a standard deviation of $0.78 \mathrm{~nm}$ using a representative sample size. Previously, Peneau et al. ${ }^{21}$ confirmed using aberration corrected microscopy that the particles in $\mathrm{AuPt} / \mathrm{TiO}_{2}$ catalysts, prepared using the same methodology, predominantly consist of alloyed $\mathrm{Au}$ and Pt. To ensure that the catalyst synthesised in this study consisted of the desired quantity of $\mathrm{Au}$ and Pt, a known quantity of the catalyst was digested in aqua regia and the resulting solution was analysed by MP-AES. The results confirmed that the catalyst has a total AuPt loading of 0.98 wt.\% and a molar ratio of $1: 0.91$ (Au : Pt). BET surface area analysis confirmed that the final catalyst exhibited a surface area of $61 \mathrm{~m}^{2} \mathrm{~g}^{-1}$, which is within the typical range of commercial Degussa $\mathrm{TiO}_{2}-\mathrm{P} 25 .{ }^{22}$

\section{Investigation into the influence of reaction conditions on the $1 \mathrm{wt} . \% \mathrm{AuPt} / \mathrm{TiO}_{2}$ catalyst}

Prior to the mechanistic investigation, the reaction conditions were first optimised to ensure that the isotopic labelling experiments were conducted under conditions which favour high LA selectivity. From the observations made by Heeres and co-workers ${ }^{17}$ over a 1 wt.\% AuPt $/ \mathrm{CeO}_{2}$ catalyst, it is known that the reaction temperature, $\mathrm{pH}$ and $\mathrm{O}_{2}$ pressure can influence the product distribution, although a detailed understanding and explanation of how these parameters affect the reaction mechanism has 
not been reported. It was therefore important to conduct similar optimisation reactions using our model AuPt/ $\mathrm{TiO}_{2}$ catalyst.

The performance of the $0.98 \mathrm{wt} . \% \mathrm{AuPt} / \mathrm{TiO}_{2}$ catalyst in this reaction was assessed over time at different temperatures, which evidently had a significant impact on both the activity and selectivity (Table 1, Figure 2(a)). As discussed previously, the reaction pathway leading to the formation of LA competes directly with a parallel oxidation route. As the reaction temperature is increased, the selectivity to LA increases at the expense of GA, TA and C-C scission products. The activity of the catalyst also clearly increases with reaction temperature, which is also reflected in the proportion of TA: GA; at higher reaction temperatures, a larger proportion of GA undergoes sequential oxidation to TA. Interestingly, reaction selectivity to $\mathrm{C}-\mathrm{C}$ scission products decreases as the reaction temperature increases. LA is fairly stable under these reaction conditions even at high temperatures. The maximum LA selectivity is observed at a reaction temperature of $120^{\circ} \mathrm{C}$, however, under these conditions there is a significant drop in the associated CMB. The highest yield of LA (ca. $68 \%$ ) is therefore observed at $100{ }^{\circ} \mathrm{C}$.

Following these experiments, the effect of $\mathrm{O}_{2}$ pressure on the product distribution and catalytic activity was investigated (Table 2, Figure 2(b)). Davis and co-workers previously demonstrated that $\mathrm{O}_{2}$ plays an indirect role in the oxidation of glycerol. ${ }^{23}$ It was established that $\mathrm{O}_{2}$ from the gas phase is not incorporated into the reaction products and concluded that the role of $\mathrm{O}_{2}$ is to act as an electron scavenger, removing electron density from the surface of the supported metal particles to liberate active sites. This too is evidenced in Table 2; under an inert atmosphere, the rate of glycerol dehydrogenation is extremely low. Interestingly as the $\mathrm{O}_{2}$ pressure is increased from 0.5 to $2 \mathrm{barg}$, a non-proportional increase in the rate of glycerol dehydrogenation is observed. This evidences that under such conditions $\mathrm{O}_{2}$ is unlikely to be chemically involved in the RDS, which is consistent with the observations by Davis and co-workers. Interestingly under higher $\mathrm{O}_{2}$ pressure (2-4 barg), the rate of dehydrogenation appears to be far more dependent on $\mathrm{O}_{2}$ pressure, which may be indicative of a change in both the reaction mechanism and role of $\mathrm{O}_{2}$ in the RDS.

As the pressure of $\mathrm{O}_{2}$ is increased from 0.5 to $3 \mathrm{barg}$, the reaction selectivity to LA remains fairly constant. At 4 barg the selectivity to LA begins to drop, which becomes more apparent as the reaction proceeds. Interestingly, the reaction selectivity to GA and TA also appears to drop as the pressure of $\mathrm{O}_{2}$ is increased. Only the reaction selectivity to $\mathrm{C}-\mathrm{C}$ cleavage products appear to increase consistently as the pressure of $\mathrm{O}_{2}$ increases. The sum of the reaction selectivity to $G A, T A$ and the products of $C-C$ remain fairly constant across all $\mathrm{O}_{2}$ pressures. This suggests that (i) $\mathrm{O}_{2}$ promotes the $\mathrm{C}-\mathrm{C}$ scission pathway and (ii) the C-C scission either occurs from GA or TA or competes with the oxidation of GLD 
to GA. Many publications have previously attributed C-C cleavages in these reactions to the in situ formation of $\mathrm{H}_{2} \mathrm{O}_{2} \cdot{ }^{9,24}$ Given that the formation of hydrogen peroxide intermediates are likely to be a product of an oxygen reduction reaction with $\mathrm{H}_{2} \mathrm{O}$, it is reasonable to suggest that increasing the pressure of $\mathrm{O}_{2}$ in the system would indeed result in an increased rate of $\mathrm{H}_{2} \mathrm{O}_{2}$ formation. The notable drop in $\mathrm{CMB}$ at 4 barg could indicate that the resultant products which arise from these cleavages are further oxidised to $\mathrm{CO}_{2}$, which is not included in our analytical procedure.

After establishing that reaction selectivity to LA is optimum at $100^{\circ} \mathrm{C}$ and 3 barg of $\mathrm{O}_{2}$, it was important to understand how influential the $\mathrm{pH}$ of the system was on the product distribution. Due to the strength of the $\mathrm{O}-\mathrm{H}$ bond under base free conditions, this process is typically considered to be ratedetermining. ${ }^{25}$ This hypothesis is supported by the data in Table 3 as the concentration of $\mathrm{NaOH}$ in the reaction appears to have no observable influence on the rate of reaction. However, under base-free conditions, the rate of reaction is substantially lower. The rate of glycerol dehydrogenation is therefore independent of $\mathrm{NaOH}$ concentration. Thereafter, competition exists between sequential oxidation to GA and the base catalysed dehydration to PALD. Both these pathways involve ${ }^{-} \mathrm{OH}$ but only the rate of dehydration appears to be dependent on its concentration.

From the data presented in Table 1, 2 and 3 and Figure 2, it is evident that the reaction conditions are exceptionally influential on the reaction selectivity over our model catalyst. Further evaluation of the initial rates under various $\mathrm{NaOH}$ and $\mathrm{O}_{2}$ pressures allowed for the derivation of a rate equation for the oxidation of glycerol. Evidently, under the optimised reaction conditions the reaction is first order with respect to $\mathrm{O}_{2}$ and zero order with respect to $\mathrm{NaOH}$. Through assumption that the reaction is first order with respect to glycerol, the total order of the reaction 2 and the rate equation may be expressed as: $\mathrm{K}=\mathrm{k}$. cat. [Glycerol $]^{1} \cdot\left[\mathrm{O}_{2}\right]^{1} \cdot[\mathrm{NaOH}]^{0}$. Following an established method, ${ }^{26,27}$ it was possible to quantify the concentration of dissolved $\mathrm{O}_{2}$ in the alkaline aqueous solutions at the different temperatures. This allowed for (i) the determination of the corresponding rate constants, (ii) the construction of an Arrhenius plot and (iii) determination of the activation energy $\left(E_{a}\right)$. The experimental activation energy calculated for the oxidation of glycerol over the $1 \mathrm{wt} . \% \mathrm{AuPt} / \mathrm{TiO} \mathrm{O}_{2}$ catalyst was $10.2 \mathrm{~kJ} \mathrm{~mol}^{-1}$, under these conditions. This is notably lower than other examples from literature of Au supported catalysts for glycerol oxidation. Activation energies of 57,50 and $35 \mathrm{KJ} \mathrm{mol}^{-1}$ have been confirmed experimentally for the oxidation of glycerol over $\mathrm{Au}$ supported on $\mathrm{Al}_{2} \mathrm{O}_{3}, \mathrm{C}$ and $\mathrm{MoO}_{3} / \mathrm{Y}^{-}$ $\mathrm{Al}_{2} \mathrm{O}_{3}$ respectively. ${ }^{28-30}$ However, it is well established that $\mathrm{AuPt} / \mathrm{TiO}_{2}$ catalysts are substantially more active than monometallic Au catalysts for this reaction, ${ }^{31}$ which could provide explanation for the lower activation energy observed in this study. 
The highest selectivity to LA at full conversion was $c a .83 \%$, which was achieved at $100{ }^{\circ} \mathrm{C}$, in the presence of $1.2 \mathrm{M}$ of $\mathrm{NaOH}$ and 3 barg $\mathrm{O}_{2}$ pressure (Table 4)..To further understand the role of the catalyst in the formation of LA, some additional experiments were conducted from DHA, GLD and PALD (Table 5). In the presence of the catalyst, selectivity to LA is either equal to or slightly lower than that observed in the absence of catalyst. Furthermore, each reaction conducted in the presence of the heterogeneous catalyst leads to the formation of Pyruvic acid (PA). The CMB for these reactions are notably lower than those observed in Tables 1-3, which is likely to be attributed to additional bimolecular pathways which occur. Based on all the aforementioned results, we can propose an updated scheme (Scheme 2).

Under alkaline conditions, glycerol adsorbs through either its primary or secondary alcohol group leading to the formation of the corresponding surface alkoxy intermediate. From the primary alkoxy intermediate, abstraction of an adjacent hydrogen leads to the desorption of GALD. GALD can then either re-adsorb and undergo as sequential oxidation to produce TA, or is consumed in a homogeneous base catalysed dehydration reaction to produce 2-hydroxypropenal (the enol form of PALD). GA can evidently be produced from GLD via base promoted reactions in the presence and absence of the catalyst. This is evidenced by the slight increase in selectivity to GA and TA observed in the catalysed and blank reactions which utilize GLD as the substrate. The 2-hydroxypropenal produced through this dehydration tautomerises to PALD, which can subsequently undergo a base catalysed rearrangement to LA or is oxidised to PA, over the catalyst.

\section{Insight on the mechanistic pathway to lactic acid from glycerol}

After dehydration of GLD, there are two possible routes by which PALD can proceed to LA; via a 2,1methide shift (Scheme 3(a)) or a 1,2-hydride shift (Scheme 3(b)). Both of these reactions are promoted by ${ }^{-} \mathrm{OH}$ and do not appear to be influenced by the presence of our heterogeneous catalyst (Table 5 ). Fortunately, distinguishing which of these two mechanisms is dominant in our system is possible as the 2,1-methide shift results in the migration of a carbon atom. As such, the position of the carbon atoms in the starting glycerol would be altered in the LA product.

To determine which of the mechanisms occur, some additional experiments were conducted using isotopically labelled ${ }^{13} \mathrm{C}$ glycerol $\left(1,3-\mathrm{di}^{-13} \mathrm{C}\right)$ in the presence of our model catalyst. This isotopic compound was selected for these experiments as the formation of $L A$ with ${ }^{13} \mathrm{C}$ in the second position, would indicate that the reaction proceeds via a 2,1-methide shift. To ensure that the performance of our model catalyst was comparable using this labelled compound, a standard reaction was conducted 
under the optimised reaction conditions (Table 4). The performance was comparable to that observed with glycerol; a slight drop in the rate of reaction and LA selectivity is observed with the $1,3-\mathrm{di}^{-13} \mathrm{C}$ glycerol which may evidence a very minor kinetic isotope effect. Nevertheless, the important conclusion to draw from these experiments is that the model $0.98 \mathrm{wt}$.\% catalyst behaves in largely the same way with both substrates and thus, we can be confident that the post dehydration reaction mechanism is the same.

Following this, samples from the reaction with $1,3-\mathrm{di}^{13}{ }^{13} \mathrm{C}$ glycerol at time $=0,60$ and 240 minutes were probed by ${ }^{13} \mathrm{C}$ NMR and the corresponding spectra are displayed in Figure 3. At $0 \mathrm{~h}$, prior to reaction (Figure $3 \mathrm{~A}$ ), only one significant ${ }^{13} \mathrm{C}$ signal is observed at a chemical shift $(\delta)$ of $62 \mathrm{ppm}$. The shift in this region is characteristic of a ${ }^{13} \mathrm{C}$ atom bonded to a hydroxide group. After 60 minutes of reaction, two additional signals appear in the ${ }^{13} \mathrm{C}$ NMR spectrum (Figure 3B). In addition to the ${ }^{13} \mathrm{C}$ shift at $62 \mathrm{ppm}$, significant signals are observed at $\delta=20$ and $182 \mathrm{ppm}$. The shift at $\delta=20 \mathrm{ppm}$ is characteristic of a ${ }^{13} \mathrm{C}$ atom in an alkyl group and given the quantitative analysis in Table 4, can be assigned to the methyl group in LA. The shift at $\delta=182 \mathrm{ppm}$ is somewhat more difficult to assign, as a shift in this region can be indicative of a ${ }^{13} \mathrm{C}$ atom double bonded to an oxygen atom in either a carbonyl or carboxylic acid group. Under alkaline conditions however, aldehydic products are not observed in this reaction and given that only trace quantities of pyruvic acid and no mesoxalic acid are observed, we can confidently assign this signal to the ${ }^{13} \mathrm{C}$ atom in a carboxylic acid group in LA. After $240 \mathrm{~min}$ of reaction (Figure 3C), the spectrum is dominated by signals at $\delta=20$ and $182 \mathrm{ppm}$. Some additional signals are also observed which likely correspond to some of other by-products formed in the reaction. If the reaction had proceeded via the alternative mechanism, a 2,1-methide shift, a dominant signal at $\delta=182 \mathrm{ppm}$ would not be observed.

Given that ${ }^{13} \mathrm{C}$ signals can be assigned to both the methyl and carboxylic acid component in LA, which appear to be in similar quantities, the mechanism to LA from PALD cannot proceed via a 2,1-methide shift and must therefore proceed through a 1,2-hydride shift. This is not necessarily surprising; while both the carbonyls in PALD activate each other to nucleophilic attack, the aldehyde is more reactive as the ketone has an additional electron-donating methyl group attached, making it less electrophilic and thus, less susceptible to undergo nucleophilic attack.

\section{Conclusion}

A model AuPt $/ \mathrm{TiO}_{2}$ catalyst was used to study the reaction mechanisms which occur in the transformation of glycerol to LA under alkaline conditions. The reaction conditions were highly 
influential on both the rate of glycerol conversion and the product distribution. The catalyst is required for the oxidative dehydrogenation of glycerol to a mixture of DHA and GALD. GALD can subsequently partake in a sequential oxidation reaction to GA, undergo $C-C$ scission or dehydration to 2hydroxypropenal, which tautomerises to PALD. There was no evidence to suggest that the heterogeneous catalyst was involved in any of the reactions leading from GALD to LA. Isotopic labelling experiments using ${ }^{13} \mathrm{C}$ glycerol were subsequently conducted and confirmed that PALD undergoes a base catalysed 1,2-hydride shift to form LA. We consider the results and discussion herein, alleviate some uncertainty within the literature, providing clarity on the mechanisms taking place in this reaction and the role of the catalyst.

\section{References}

${ }^{1}$ U.I. Nda-Umar, I. Ramli, Y.H. Taufiq-Yap, and E.N. Muhamad, Catalysts 9, (2019).

${ }^{2}$ L. Prati and M. Rossi, J. Catal. 176, 552 (1998).

${ }^{3}$ G. Dodekatos, S. Schünemann, and H. Tüysüz, ACS Catal. 8, 6301 (2018).

${ }^{4}$ C.H. Zhou, J.N. Beltramini, Y.X. Fan, and G.Q. Lu, Chem. Soc. Rev. 37, 527 (2008).

${ }^{5}$ Y. Wang, Y. Xiao, and G. Xiao, Chinese J. Chem. Eng. 27, 1536 (2019).

${ }^{6}$ A. Villa, N. Dimitratos, C.E. Chan-Thaw, C. Hammond, L. Prati, and G.J. Hutchings, Acc. Chem. Res. 48, 1403 (2015).

${ }^{7}$ N. Razali and A.Z. Abdullah, Appl. Catal. A Gen. 543, 234 (2017).

${ }^{8}$ J. Fu, Q. He, P.J. Miedziak, G.L. Brett, X. Huang, S. Pattisson, M. Douthwaite, and G.J. Hutchings, Chem. - A Eur. J. 24, 2396 (2018).

${ }^{9}$ D. Wang, A. Villa, D. Su, L. Prati, and R. Schlögl, ChemCatChem 5, 2717 (2013).

${ }^{10}$ H. Yin, C. Zhang, H. Yin, D. Gao, L. Shen, and A. Wang, Chem. Eng. J. 288, 332 (2016).

${ }^{11}$ H. Yin, H. Yin, A. Wang, L. Shen, Y. Liu, and Y. Zheng, J. Nanosci. Nanotechnol. 17, 1255 (2017).

${ }^{12}$ D. Roy, B. Subramaniam, and R. V. Chaudhari, ACS Catal. 1, 548 (2011).

${ }^{13}$ S.A. Zavrazhnov, A.L. Esipovich, S.M. Danov, S.Y. Zlobin, and A.S. Belousov, Kinet. Catal. 59, 459 (2018).

${ }^{14}$ R. Abdullah, S.N. Mohamed Saleh, K. Embong, and A.Z. Abdullah, Chem. Eng. Commun. 1 (2019).

${ }^{15}$ Z. Tang, S.L. Fiorilli, H.J. Heeres, and P.P. Pescarmona, ACS Sustain. Chem. Eng. 6, 10923 (2018).

${ }^{16}$ K.M.A. Santos, E.M. Albuquerque, G. Innocenti, L.E.P. Borges, C. Sievers, and M.A. Fraga, ChemCatChem 11, 3054 (2019).

${ }^{17}$ R.K.P. Purushothaman, J. van Haveren, D.S. van Es, I. Melián-Cabrera, J.D. Meeldijk, and H.J. Heeres, Appl. Catal. B Environ. 147, 92 (2014).

${ }^{18}$ V. A. Yaylayan, S. Harty-Majors, and A. A. Ismail, Carbohydr. Res. 318, 20 (1999). 
${ }^{19}$ R.W. Nagorski and J.P. Richard, J. Am. Chem. Soc. 123, 794 (2001).

${ }^{20}$ A. Villa, D. Wang, G.M. Veith, F. Vindigni, and L. Prati, Catal. Sci. Technol. 3, 3036 (2013).

${ }^{21}$ V. Peneau, Q. He, G. Shaw, S.A. Kondrat, T.E. Davies, P. Miedziak, M. Forde, N. Dimitratos, C.J. Kiely, and G.J. Hutchings, Phys. Chem. Chem. Phys. 15, 10636 (2013).

${ }^{22}$ X. Wang, S.O. Pehkonen, J. Rämö, M. Väänänen, J.G. Highfield, and K. Laasonen, Catal. Sci. Technol. 2, 784 (2012).

${ }^{23}$ B.N. Zope, D.D. Hibbitts, M. Neurock, and R.J. Davis, Science (80-. ). 330, 74 (2010).

${ }^{24}$ W.C. Ketchie, M. Murayama, and R.J. Davis, Top. Catal. 44, 307 (2007).

${ }^{25}$ Q. Gu, P. Sautet, and C. Michel, ACS Catal. 8, 11716 (2018).

${ }^{26}$ W. Xing, G. Yin, and J. Zhang, Rotating Electrode Methods and Oxygen Reduction Electrocatalysts (2014).

${ }^{27}$ A. Schumpe, I. Adler, and W. -D Deckwer, Biotechnol. Bioeng. 20, 145 (1978).

28 J. Díaz, E. Skrzyńska, J.-S. Girardon, M. Capron, F. Dumeignil, and P. Fongarland, ChemEngineering 1, 7 (2017).

${ }^{29}$ S. Demirel, M. Lucas, J. Wärnå, T. Salmi, D. Murzin, and P. Claus, Top. Catal. 44, 299 (2007).

${ }^{30}$ T.A. Ntho, P. Gqogqa, and J.L. Aluha, in Adv. Chem. Kinet. (2018).

${ }^{31}$ A. Villa, A. Jouve, F.J. Sanchez Trujillo, D. Motta, L. Prati, and N. Dimitratos, Catalysts 8, (2018).

\section{$\underline{\text { Schemes }}$}

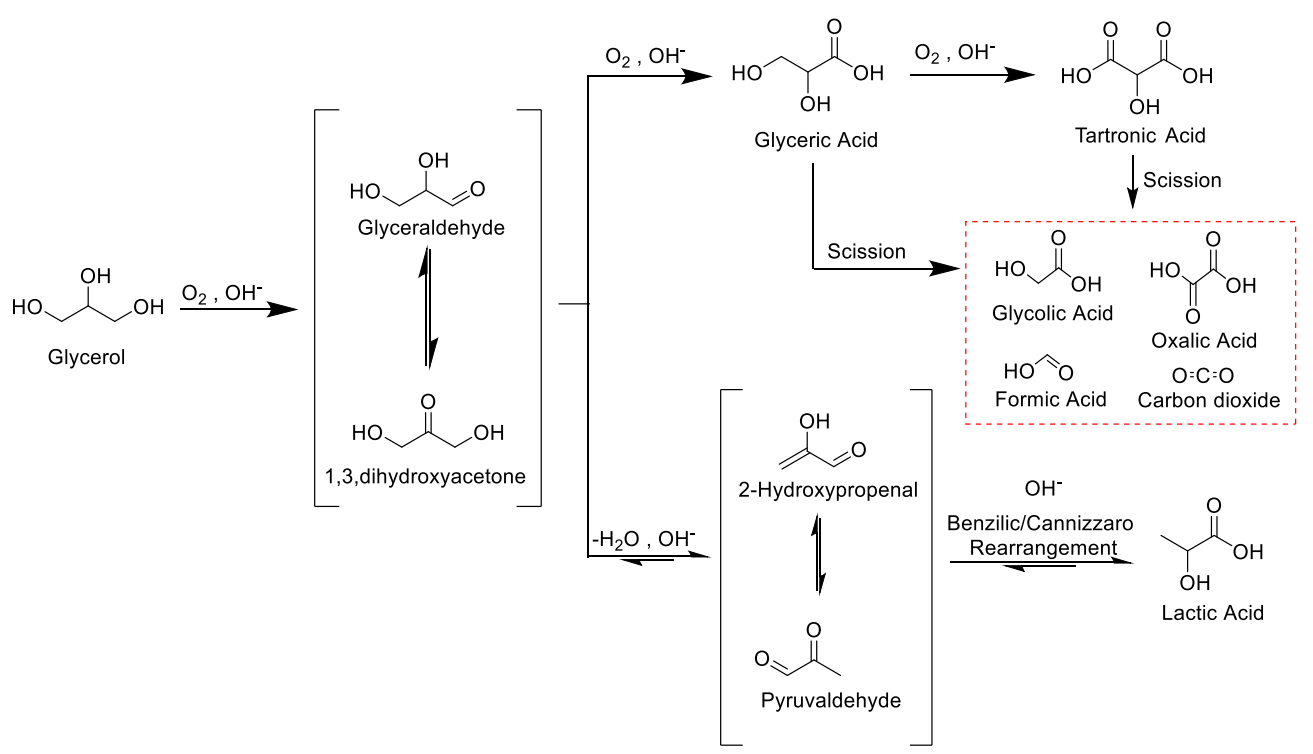

Scheme 1. Reaction scheme illustrating the different products which can form during the aerobic oxidation of glycerol in alkaline conditions over noble metal supported catalysts. The red dotted lines correspond to products formed from scission of either glyceric acid or tartronic acid. 
<smiles>OCC(O)COCC(O)C(CO)C(O)CO</smiles>

2.<smiles>[Z20]C(O)C(CO)C(=O)CC#CCCCCCO</smiles>
$\downarrow \Theta_{\mathrm{OH}}$<smiles>OCC(CO)OC1CC1</smiles>

4. $\mathrm{OH}$<smiles>CCC(C)=CC=O</smiles><smiles>C1CCCC1</smiles>

5. O

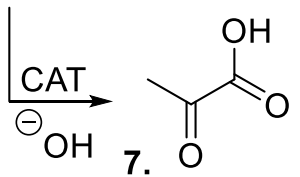

8.<smiles>C=CCC(=O)CO</smiles>

8.
3.<smiles>O=C(O)C(O)CO</smiles><smiles>CC(C)C(=O)O</smiles>

6. $\mathrm{OH}$<smiles>OC[C@H]1O[C@H]2CC[C@H]1C2(CO)CO</smiles>

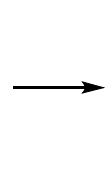

Scheme 2. Proposed mechanisms for the transformation of glycerol under alkaline conditions. KEY: 1. Glycerol; 2. Glyceraldehyde; 3. Glyceric acid; 4. 2-Hydroxypropenal ; 5. Pyruvaldehyde; 6. Lactic acid; 7. Pyruvic acid; 8. Dihydroxyacetone.

(a)<smiles>CC(=O)C=O</smiles>

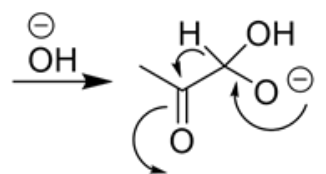<smiles>CCCCCC(O)C(=O)O</smiles>

(b)<smiles>CC(=O)C=O</smiles><smiles>CC(O)(O)C(=O)CCCCCCCO</smiles><smiles>CCCCCC(=O)O</smiles>

Scheme 3: Mechanisms for the base catalysed transformation of pyruvaldehyde to lactic acid. Under alkaline conditions, lactic acid may be produced via (a) a 1,2-hydride shift or (b) 2,1-methide shift.

* is used to illustrate the location of ${ }^{13} \mathrm{C}$ isotopes in lactic acid for each reaction mechanism. 


\section{Figures}
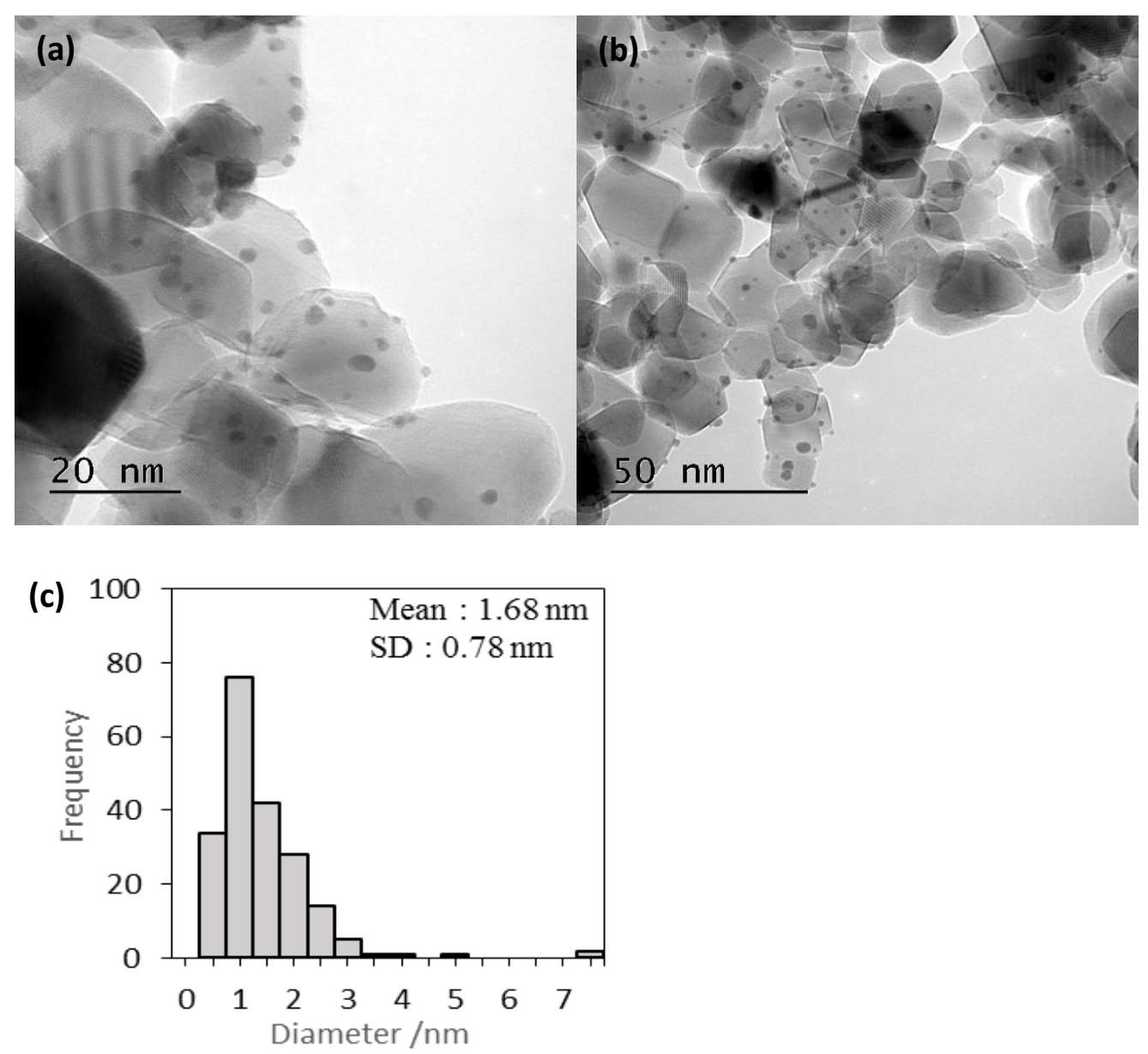

Figure 1. Transmission electron micrographs of the model AuPt/ $/ \mathrm{TO}_{2}$ catalyst prepared by solimmobilisation. (a) and (b) correspond to images with a $20 \mathrm{~nm}$ and $50 \mathrm{~nm}$ insert, respectively. (c) is a histogram evidencing the size distribution of the supported AuPt particles. 

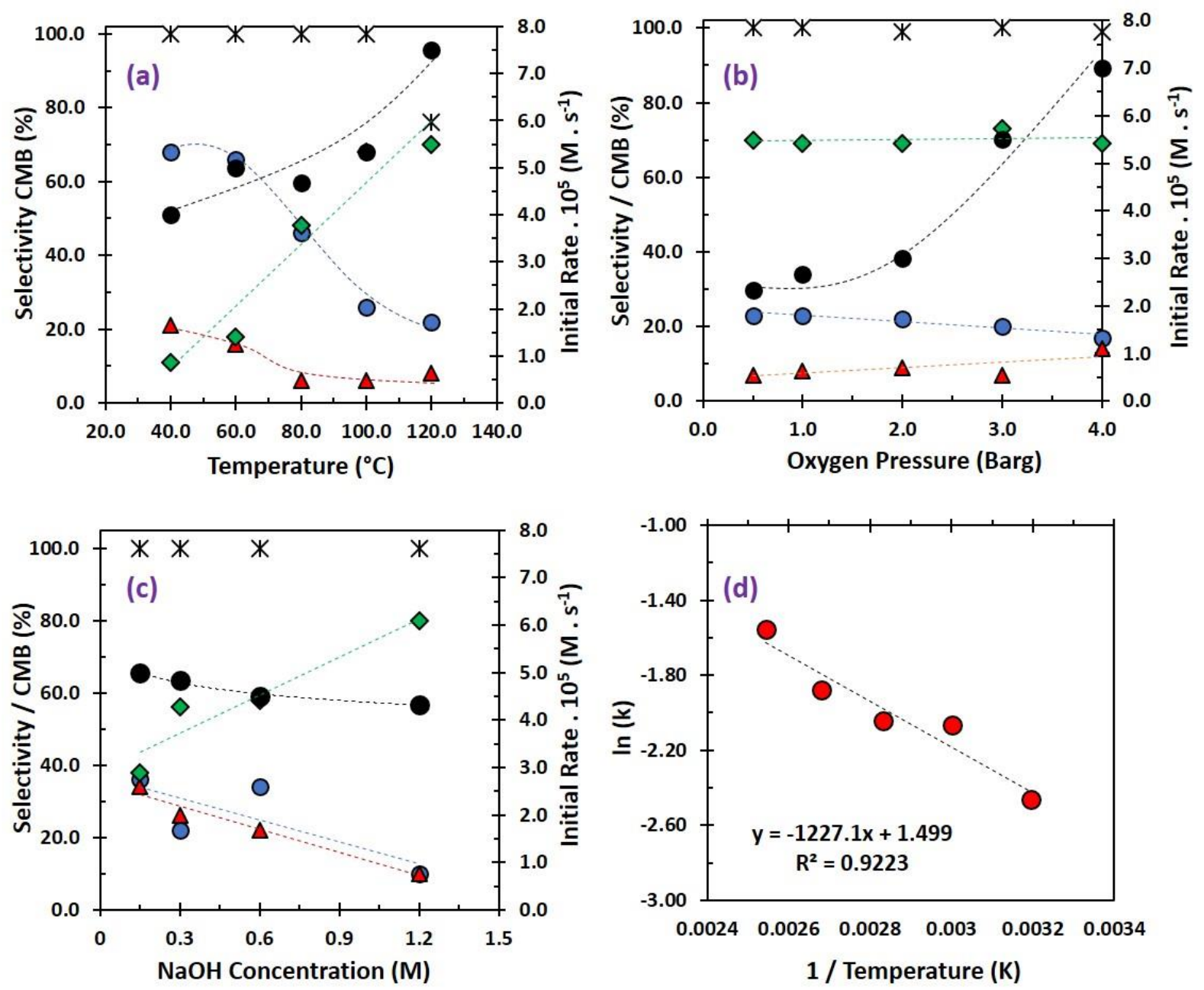

Figure 2. The influence of temperature (a), $\mathrm{O}_{2}$ pressure (b) and $\mathrm{NaOH}$ concentration (c) on the reaction selectivity, carbon mass balance and initial rate for the oxidation of glycerol over the $1 \mathrm{wt} . \% \mathrm{AuPt} / \mathrm{TiO}_{2}$ catalyst. The Arrhenius plot (d) is used to calculate the experimental activation energy for glycerol oxidation. To ensure fair comparison, the data points in (a), (b) and (c) are collected at iso-conversion; conversion $=100 \%$ for $(a), 72-84 \%$ for (b) and $100 \%$ for (c). The initial rate data was generated after 30 minutes $(1800 \mathrm{~s})$ of reaction. Key: Initial rate $\bullet$; lactic acid selectivity $\diamond$; direct oxidation selectivity $\mathrm{O}$; C-C scission selectivity $\Delta$; Carbon Mass Balance $*$. Note: Selectivity to direct oxidation products is the sum of reaction selectivity to glyceric and tartronic acid. 


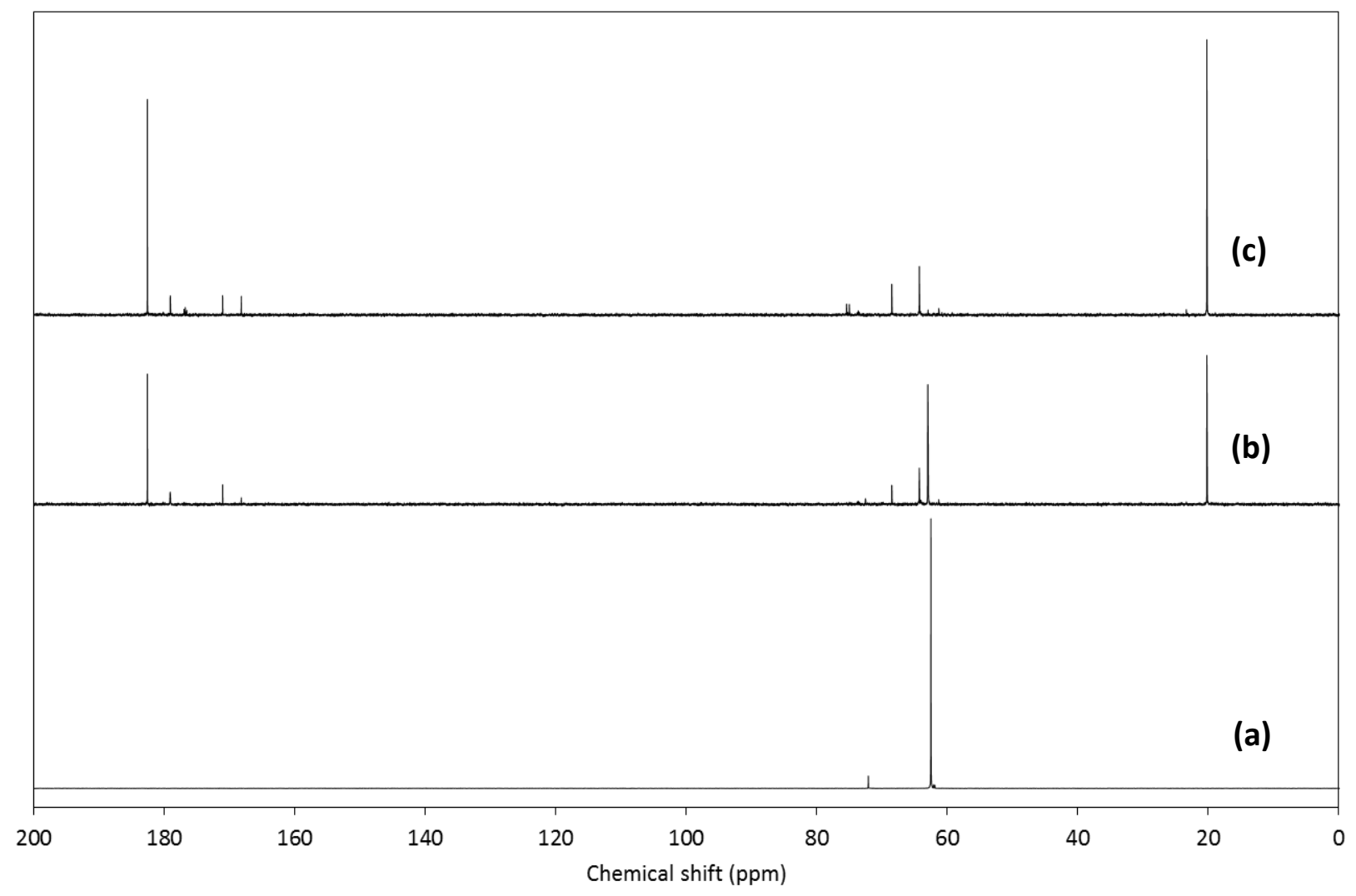

Figure 3. NMR spectra corresponding to reactions of $1,3-\mathrm{di}^{13}{ }^{13} \mathrm{C}$ glycerol over the AuPt/TiO $\mathrm{T}_{2}$ catalyst after 0 (A), 60 (B) and 240 (C) minutes. Reaction conditions: $10 \mathrm{~mL}$ reaction volume, Glycerol (0.3 M), $\mathrm{NaOH}(1.2 \mathrm{M}), \mathrm{O}_{2}$ pressure (3 barG), metal: substrate ratio $1000: 1$, reaction temperature $\left(100^{\circ} \mathrm{C}\right)$. 


\section{$\underline{\text { Tables }}$}

Table 1. The influence of the reaction temperature on the glycerol conversion and selectivity profile of the reaction products, over the model $\mathrm{AuPt} / \mathrm{TiO}_{2}$ catalyst.

\begin{tabular}{|c|c|c|c|c|c|c|c|}
\hline \multirow{2}{*}{$\begin{array}{c}\text { Temperature } \\
\left({ }^{\circ} \mathrm{C}\right)\end{array}$} & \multirow[b]{2}{*}{$\begin{array}{l}\text { Time } \\
(\min )\end{array}$} & \multirow[b]{2}{*}{$\begin{array}{c}\text { Conversion } \\
(\%)\end{array}$} & \multirow[b]{2}{*}{$\begin{array}{c}\text { CMB } \\
(\%)\end{array}$} & \multicolumn{4}{|c|}{ Selectivity (\%) } \\
\hline & & & & GA & TA & C-C Scission & LA \\
\hline \multirow{4}{*}{40} & 30 & 24 & 100 & 65 & 3 & 21 & 11 \\
\hline & 60 & 48 & 99 & 66 & 3 & 19 & 12 \\
\hline & 120 & 89 & 100 & 64 & 5 & 21 & 10 \\
\hline & 240 & 100 & 100 & 63 & 5 & 21 & 11 \\
\hline \multirow{4}{*}{60} & 30 & 30 & 101 & 62 & 3 & 12 & 23 \\
\hline & 60 & 59 & 99 & 61 & 5 & 13 & 21 \\
\hline & 120 & 92 & 98 & 61 & 6 & 14 & 19 \\
\hline & 240 & 100 & 100 & 59 & 7 & 16 & 18 \\
\hline \multirow{4}{*}{80} & 30 & 28 & 100 & 38 & 6 & 11 & 45 \\
\hline & 60 & 64 & 99 & 36 & 8 & 11 & 45 \\
\hline & 120 & 97 & 99 & 35 & 11 & 8 & 46 \\
\hline & 240 & 100 & 100 & 31 & 15 & 6 & 48 \\
\hline \multirow{4}{*}{100} & 30 & 32 & 99 & 20 & 8 & 4 & 68 \\
\hline & 60 & 68 & 101 & 16 & 10 & 5 & 69 \\
\hline & 120 & 100 & 98 & 12 & 15 & 5 & 68 \\
\hline & 240 & 100 & 100 & 10 & 16 & 6 & 68 \\
\hline \multirow{4}{*}{120} & 30 & 45 & 95 & 16 & 9 & 4 & 71 \\
\hline & 60 & 88 & 87 & 14 & 8 & 6 & 72 \\
\hline & 120 & 100 & 80 & 12 & 10 & 6 & 72 \\
\hline & 240 & 100 & 76 & 11 & 11 & 8 & 70 \\
\hline
\end{tabular}

Reaction conditions; $10 \mathrm{~mL}$ reaction volume, Glycerol $(0.3 \mathrm{M}), \mathrm{NaOH}(0.6 \mathrm{M}), \mathrm{O}_{2}$ pressure (1 barG), metal: substrate ratio 1000:1, $4 \mathrm{~h}$ reaction time and reaction temperature $\left(40-120^{\circ} \mathrm{C}\right)$. Key: CMB (carbon mass balance); GA (glyceric acid); TA (tartronic acid); C-C Scission (oxalic acid, formic acid, glycolic acid); LA (lactic acid). 
Table 2. The influence of $\mathrm{O}_{2}$ pressure on the glycerol conversion and selectivity profile of the reaction products, over the model $\mathrm{AuPt} / \mathrm{TiO}_{2}$ catalyst.

\begin{tabular}{|c|c|c|c|c|c|c|c|}
\hline \multirow{2}{*}{$\begin{array}{c}\text { Oxygen } \\
\text { Pressure } \\
\text { (barg) }\end{array}$} & \multirow[b]{2}{*}{$\begin{array}{l}\text { Time } \\
(\min )\end{array}$} & \multirow[b]{2}{*}{$\begin{array}{c}\text { Conversion } \\
(\%)\end{array}$} & \multirow[b]{2}{*}{$\begin{array}{l}\text { CMB } \\
(\%)\end{array}$} & \multicolumn{4}{|c|}{ Selectivity / \% } \\
\hline & & & & GA & TA & C-C Scission & LA \\
\hline \multirow{4}{*}{$\mathrm{He}^{*}$} & 30 & 1 & 100 & 40 & 0 & 0 & 60 \\
\hline & 60 & 1 & 100 & 34 & 0 & 7 & 59 \\
\hline & 120 & 2 & 100 & 18 & 0 & 23 & 59 \\
\hline & 240 & 3 & 100 & 10 & 1 & 30 & 59 \\
\hline \multirow{4}{*}{0.5} & 30 & 14 & 100 & 26 & 0 & 1 & 73 \\
\hline & 60 & 28 & 100 & 25 & 0 & 4 & 71 \\
\hline & 120 & 67 & 101 & 24 & 1 & 5 & 70 \\
\hline & 240 & 78 & 100 & 22 & 1 & 7 & 70 \\
\hline \multirow{4}{*}{1.0} & 30 & 16 & 101 & 25 & 0 & 3 & 72 \\
\hline & 60 & 36 & 99 & 24 & 1 & 5 & 70 \\
\hline & 120 & 72 & 100 & 22 & 1 & 8 & 69 \\
\hline & 240 & 88 & 101 & 21 & 2 & 9 & 68 \\
\hline \multirow{4}{*}{2.0} & 30 & 18 & 100 & 24 & 0 & 6 & 70 \\
\hline & 60 & 44 & 101 & 23 & 1 & 8 & 68 \\
\hline & 120 & 84 & 99 & 20 & 2 & 9 & 69 \\
\hline & 240 & 94 & 100 & 17 & 3 & 11 & 69 \\
\hline \multirow{4}{*}{3.0} & 30 & 33 & 100 & 20 & 1 & 5 & 74 \\
\hline & 60 & 73 & 100 & 19 & 1 & 7 & 73 \\
\hline & 120 & 96 & 99 & 15 & 2 & 11 & 72 \\
\hline & 240 & 100 & 101 & 12 & 4 & 13 & 71 \\
\hline \multirow{4}{*}{4.0} & 30 & 42 & 100 & 16 & 1 & 11 & 72 \\
\hline & 60 & 79 & 99 & 15 & 2 & 14 & 69 \\
\hline & 120 & 100 & 97 & 14 & 3 & 18 & 65 \\
\hline & 240 & 100 & 95 & 5 & 12 & 18 & 65 \\
\hline
\end{tabular}

Reaction conditions; $10 \mathrm{~mL}$ reaction volume, Glycerol (0.3 M), $\mathrm{NaOH}(0.6 \mathrm{M}), \mathrm{O}_{2}\left(0.5-4\right.$ barG) - $\mathrm{He}^{*}$ corresponds to reaction run under 3 barG of He, metal: substrate ratio 1000:1, $4 \mathrm{~h}$ reaction time and $100{ }^{\circ} \mathrm{C}$. Key: CMB (carbon mass balance); GA (glyceric acid); TA (tartronic acid); C-C Scission (oxalic acid, formic acid, glycolic acid); LA (lactic acid). 
Table 3. The influence of $\mathrm{NaOH}$ concentration on the glycerol conversion and selectivity profile of the reaction products, over the model $\mathrm{AuPt} / \mathrm{TiO}_{2}$ catalyst.

\begin{tabular}{|c|c|c|c|c|c|c|c|c|}
\hline \multirow{2}{*}{$\begin{array}{c}\mathrm{NaOH} \\
\text { Concentration } \\
\text { (M) }\end{array}$} & \multirow[b]{2}{*}{$\begin{array}{l}\text { Time } \\
(\min )\end{array}$} & \multirow[b]{2}{*}{$\begin{array}{c}\text { Conversion } \\
(\%)\end{array}$} & \multirow[b]{2}{*}{$\begin{array}{c}\text { CMB } \\
(\%)\end{array}$} & \multicolumn{5}{|c|}{ Selectivity (\%) } \\
\hline & & & & GA & TA & DHA & LA & $\begin{array}{c}\text { C-C } \\
\text { Scission }\end{array}$ \\
\hline \multirow{4}{*}{0} & 30 & 1 & 99 & 10 & 1 & 79 & 0 & 10 \\
\hline & 60 & 5 & 100 & 8 & 1 & 67 & 0 & 24 \\
\hline & 120 & 8 & 100 & 7 & 2 & 61 & 0 & 30 \\
\hline & 240 & 11 & 100 & 5 & 3 & 58 & 0 & 34 \\
\hline \multirow{4}{*}{0.15} & 30 & 30 & 100 & 42 & 4 & 0 & 35 & 19 \\
\hline & 60 & 64 & 100 & 41 & 5 & 0 & 36 & 18 \\
\hline & 120 & 97 & 99 & 35 & 7 & 0 & 37 & 21 \\
\hline & 240 & 100 & 100 & 28 & 8 & 0 & 38 & 26 \\
\hline \multirow{4}{*}{0.3} & 30 & 29 & 99 & 28 & 4 & 0 & 55 & 13 \\
\hline & 60 & 59 & 100 & 25 & 7 & 0 & 54 & 14 \\
\hline & 120 & 92 & 100 & 18 & 9 & 0 & 55 & 18 \\
\hline & 240 & 100 & 100 & 8 & 14 & 0 & 56 & 22 \\
\hline \multirow{4}{*}{0.6} & 30 & 27 & 99 & 29 & 2 & 0 & 68 & 9 \\
\hline & 60 & 55 & 100 & 27 & 7 & 0 & 65 & 10 \\
\hline & 120 & 88 & 100 & 29 & 12 & 0 & 58 & 14 \\
\hline & 240 & 100 & 100 & 16 & 18 & 0 & 58 & 13 \\
\hline \multirow{4}{*}{1.2} & 30 & 26 & 100 & 16 & 2 & 0 & 78 & 4 \\
\hline & 60 & 52 & 99 & 11 & 6 & 0 & 78 & 5 \\
\hline & 120 & 78 & 100 & 5 & 8 & 0 & 79 & 8 \\
\hline & 240 & 100 & 100 & 0 & 10 & 0 & 80 & 10 \\
\hline
\end{tabular}

Reaction conditions; $10 \mathrm{~mL}$ reaction volume, Glycerol $(0.3 \mathrm{M}), \mathrm{NaOH}(0-1.2 \mathrm{M}), \mathrm{O}_{2}$ pressure (3 barG), metal: substrate ratio 1000:1, $4 \mathrm{~h}$ reaction time and $100^{\circ} \mathrm{C}$. Key: $\mathrm{CMB}$ (carbon mass balance); GA (glyceric acid); TA (tartronic acid); C-C Scission (oxalic acid, formic acid, glycolic acid); LA (lactic acid). 
Table 4. The substrate conversion and the selectivity profile of the reaction products which are formed in a reaction over the model $\mathrm{AuPt} / \mathrm{TiO}_{2}$ catalyst under optimised reaction conditions.

\begin{tabular}{|c|c|c|c|c|c|c|c|}
\hline \multirow{2}{*}{ Substrate } & \multirow{2}{*}{$\begin{array}{l}\text { Time } \\
\text { (min) }\end{array}$} & \multirow{2}{*}{$\begin{array}{c}\text { Conversion } \\
\text { (\%) }\end{array}$} & \multirow{2}{*}{$\begin{array}{c}\text { Carbon } \\
\text { balance } \\
(\%)\end{array}$} & \multicolumn{4}{|c|}{ Selectivity (\%) } \\
\hline & & & & GA & TA & C-C Scission & LA \\
\hline \multirow{4}{*}{ Glycerol } & 30 & 31 & 99 & 14 & 2 & 3 & 81 \\
\hline & 60 & 56 & 100 & 9 & 4 & 5 & 82 \\
\hline & 120 & 89 & 100 & 6 & 4 & 7 & 83 \\
\hline & 240 & 100 & 100 & 5 & 4 & 8 & 83 \\
\hline \multirow{4}{*}{$\begin{array}{c}\text { 1,3-di-13C } \\
\text { Glycerol }\end{array}$} & 30 & 28 & 99 & 14 & 2 & 5 & 79 \\
\hline & 60 & 49 & 100 & 11 & 4 & 7 & 78 \\
\hline & 120 & 85 & 100 & 8 & 4 & 9 & 79 \\
\hline & 240 & 100 & 100 & 7 & 4 & 10 & 79 \\
\hline
\end{tabular}

Reaction conditions; $10 \mathrm{~mL}$ reaction volume, Glycerol (0.3 M), NaOH (1.2 M), $\mathrm{O}_{2}$ pressure (3 barG), metal: substrate ratio 1000:1, $4 \mathrm{~h}$ reaction time and $100^{\circ} \mathrm{C}$. Key: $\mathrm{CMB}$ (carbon mass balance); GA (glyceric acid); TA (tartronic acid); C-C Scission (oxalic acid, formic acid, glycolic acid); LA (lactic acid). 
Table 5: The aerobic oxidation of dihydroxyacetone, glyceraldehyde and pyruvaldehyde in the presence and absence of the model $\mathrm{AuPt} / \mathrm{TiO}_{2}$ catalyst, under basic conditions.

\begin{tabular}{|c|c|c|c|c|c|c|c|c|}
\hline \multirow{2}{*}{ Substrate } & \multirow{2}{*}{ Catalyst } & \multirow{2}{*}{ Conv. \% } & \multicolumn{4}{|c|}{ Selectivity (\%) } & & \multirow{2}{*}{$\begin{array}{c}\mathrm{CMB} \\
\text { (\%) }\end{array}$} \\
\hline & & & $\mathrm{GA}$ & TA & C-C Scission & $\mathrm{LA}$ & PA & \\
\hline \multirow{2}{*}{ DHA } & Yes & 98 & 15 & 6 & 24 & 51 & 4 & 52 \\
\hline & No & 97 & 20 & 3 & 25 & 52 & 0 & 57 \\
\hline \multirow{2}{*}{ GLD } & Yes & 100 & 18 & 8 & 26 & 46 & 2 & 66 \\
\hline & No & 100 & 18 & 3 & 27 & 53 & 0 & 62 \\
\hline \multirow{2}{*}{ PALD } & Yes & 100 & 0 & 0 & 5 & 92 & 4 & 97 \\
\hline & No & 100 & 0 & 0 & 5 & 96 & 0 & 88 \\
\hline
\end{tabular}

Reaction conditions; $10 \mathrm{~mL}$ reaction volume, substrate $(0.1 \mathrm{M}), \mathrm{NaOH}(0.4 \mathrm{M}), \mathrm{O}_{2}$ pressure (3 barG), metal: substrate ratio $1000: 1,0.5 \mathrm{~h}$ reaction time and $100^{\circ} \mathrm{C}$. Key: CMB (carbon mass balance); GA (glyceric acid); TA (tartronic acid); C-C Scission (oxalic acid, formic acid, glycolic acid); LA (lactic acid); PA (pyruvic acid). 